\title{
Multiple virulence factors regulated by AlgU contribute to the pathogenicity of Pseudomonas savastanoi pv. glycinea in soybean
}

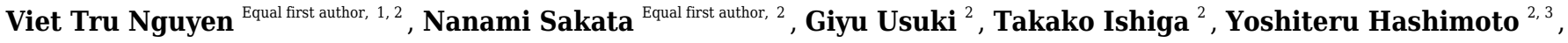 \\ Yasuhiro Ishiga ${ }^{\text {Corresp. } 2}$ \\ ${ }^{1}$ Western Highlands Agriculture and Forestry Science Institute, Buon Ma Thuot, Daklak, Vietnam \\ 2 Faculty of Life and Environmental Sciences, University of Tsukuba, Tsukuba, Ibaraki, Japan \\ 3 Microbiology Research Center for Sustainability (MiCS), University of Tsukuba, Tsukuba, Ibaraki, Japan \\ Corresponding Author: Yasuhiro Ishiga \\ Email address: ishiga.yasuhiro.km@u.tsukuba.ac.jp
}

Pseudomonas savastanoi pv. glycinea (Psg) causes bacterial blight of soybean. To identify candidate virulence factors, transposon-mediated mutational analysis of Psg was carried out. We syringe-inoculated soybean leaves with Psg transposon mutants and identified 28 mutants which showed reduced virulence from 1,000 mutants screened. Next, we sprayinoculated soybean leaves with these mutants and demonstrated that the algU mutant showed significantly reduced virulence together with reduced bacterial populations in planta. Expression profiles comparison between the Psg wild-type (WT) and algU mutant in $\mathrm{HSC}$ broth revealed that expression of coronatine (COR)-related genes (including $\mathrm{cmaA}$ and corR) were down-regulated in the algU mutant compared with Psg WT. Moreover, we also showed that COR production were reduced in the algU mutant compared with WT. We also demonstrated that $\operatorname{alg} D$, which is related to alginate biosynthesis, showed reduced expression and biofilm formation was significantly suppressed in the algU mutant. Furthermore, $h r p L$ also showed less expression in the algU mutant. These results indicate that AlgU plays a critical role in promoting Psg pathogenesis by regulating multiple virulence factors. 
1 Multiple virulence factors regulated by AlgU contribute

2 to the pathogenicity of Pseudomonas savastanoi pv.

3 glycinea in soybean

Viet Tru Nguyen ${ }^{1,2 *}$, Nanami Sakata ${ }^{1 *}$, Giyu Usuki ${ }^{1}$, Takako Ishiga ${ }^{1}$, Yoshiteru Hashimoto ${ }^{1,3}$ and Yasuhiro Ishiga ${ }^{1}$

${ }^{1}$ Faculty of Life and Environmental Sciences, University of Tsukuba, 1-1-1 Tennodai, Tsukuba, Ibaraki 305-8572, Japan.

${ }^{2}$ Western Highlands Agriculture and Forestry Science Institute, 53 Nguyen Luong Bang Street, Buon Ma Thuot City, Daklak Province, Vietnam.

${ }^{3}$ Microbiology Research Center for Sustainability (MiCS), University of Tsukuba, 1-1-1 Tennodai, Tsukuba, Ibaraki 305-8572, Japan.

*These authors contributed equally to this work.

Corresponding Author:

Yasuhiro Ishiga ${ }^{1}$

1-1-1 Tennodai, Tsukuba, Ibaraki 305-8572, Japan.

Email address: ishiga.yasuhiro.km@u.tsukuba.ac.jp

\section{Abstract}

Pseudomonas savastanoi pv. glycinea (Psg) causes bacterial blight of soybean. To identify candidate virulence factors, transposon-mediated mutational analysis of Psg was carried out. We syringe-inoculated soybean leaves with $P s g$ transposon mutants and identified 28 mutants which showed reduced virulence from 1,000 mutants screened. Next, we spray-inoculated soybean leaves with these mutants and demonstrated that the alg $U$ mutant showed significantly reduced virulence together with reduced bacterial populations in planta. Expression profiles comparison between the $P s g$ wild-type (WT) and $\operatorname{alg} U$ mutant in HSC broth revealed that expression of coronatine (COR)related genes (including $c m a A$ and $\operatorname{corR}$ ) were down-regulated in the $\operatorname{alg} U$ mutant compared with Psg WT. Moreover, we also showed that COR production were reduced in the algU mutant compared with WT. We also demonstrated that $\operatorname{alg} D$, which is related to alginate biosynthesis, showed reduced expression and biofilm formation was significantly suppressed in the $\operatorname{alg} U$ mutant. Furthermore, $h r p L$ also showed less expression in the $\operatorname{alg} U$ mutant. These results indicate that $\mathrm{AlgU}$ plays a critical role in promoting $P s g$ pathogenesis by regulating multiple virulence factors.

\section{Introduction}


40

41

42

43

44

45

46

47

48

49

50

51

52

53

54

55

56

57

58

59

60

61

62

63

64

65

66

67

68

69

70

71

72

73

74

75

76

77

78

79

Pseudomonas savastanoi pv. glycinea (Psg) causes bacterial blight of soybean. The disease is characterized by circular necrotic lesions on leaves surrounded by a chlorotic halo (Ignjatov et al., 2007). In P. syringae, P. cannabina, and P. savastanoi, the phytotoxin Coronatine (COR) is important in inducing chlorosis, and contributes to bacterial growth and lesion formation (Bender et al., 1987; Budde and Ullrich, 2000; Peñaloza-Vázquez et al., 2000; Uppalapati et al., 2005; Qi et al., 2011; Sakata et al., 2021). In Psg PG4180, COR synthesis genes reside on a $90 \mathrm{~kb}$ plasmid designated p4180A (Bender et al., 1991), with a $32 \mathrm{~kb}$ COR gene cluster which consists of two distinct regions encoding coronafacic acid (CFA) and coronamic acid (CMA) (Bender, 1999). Psg produces COR not only for the biological fitness of pathogens in planta (Ullrich et al., 1993) but also in vitro (Hoitink and Sinden, 1970; Palmer and Bender, 1993). Many studies showed the roles of COR in chlorosis, promoting lesion formation, and suspension of both stomatal and salicylic acid (SA)-dependent defenses (Peñaloza-Vázquez et al., 2000; Kloek et al., 2001; Zhao et al., 2003; Brooks et al., 2005; Melotto et al., 2006; Uppalapati et al., 2007). COR contributes to $P$. syringae pv. tomato (Pst) DC3000 virulence by suppressing the host defense response (Uppalapati et al., 2007). COR suppresses pathogen-associated molecular pattern (PAMP)-triggered immunity (PTI), especially stomatal-based defense in the early Pst DC3000 infection stage in Arabidopsis thaliana and tomato (Melotto et al., 2006; Ishiga et al., 2018).

Besides COR, the type three secretion system (T3SS) also plays a critical role in $P$. syringae virulence. The T3SS, is encoded by the hrp (hypersensitive response and pathogenicity) cluster, and transfers type three effectors (T3Es) into plant cells to suppress PTI, contribute to pathogenesis, and enhance disease symptoms and bacterial multiplication (Brooks et al., 2005; Lam et al., 2014). Furthermore, Psg also produces pectolytic enzymes which allow the pathogen to invade and multiply in the intercellular spaces of host tissues. This is the physiological capability of Psg in using plant polysaccharides and providing flexibility for its pathogen activity (Haefelet and Lindow, 1987).

$\mathrm{AlgU}$, an extracytoplasmic function (ECF) sigma factor, is also important in supporting $P$. syringae growth and disease development (Markel et al., 2016). AlgU regulates between 800 to 1,000 genes (Yu et al., 2014), and importantly contributes to virulence gene regulation as well as flagellin repression (Schreiber and Desveaux, 2011; Markel et al., 2016; Bao et al., 2020). Pst DC3000 AlgU is not only able to regulate gene expression associated with T3SEs and the phytotoxin COR, but also alginate biosynthesis (Ishiga et al., 2018). Moreover, AlgU (previously called AlgT) also induces transcription of the $\operatorname{alg} T-m u c A B$ gene cluster and the $\operatorname{alg} D$ operon, which are responsible for alginate biosynthesis in Psg PG4180 (Schenk et al., 2006). Although AlgU has been extensively studied in several $P$. syringae pathovars, its roles in Psg pathogenicity have not been elucidated yet.

To identify genes related to $P$. syringae pathogenicity, researchers carried out a screen for $P$. syringae mutants with reduced virulence. Pst DC3000 Tn5 mutants with reduced virulence on A. thaliana found the crucial functions of COR in virulence (Brooks et al., 2004). Sakata et al., (2019) also screened for P. cannabina pv. alisalensis (Pcal) KB211 Tn5 mutants with reduced virulence on cabbage plants using a dip-inoculation method, and identified multiple virulence 
80 factors including the T3SS, membrane transporters, transcription factors, and amino acid 81 metabolism genes. Thus, it is tempting to speculate that each $P$. syringae pathovar has developed 82 its own virulence factors. However, a screening study to identify Psg virulence factors has not 83 been conducted previously.

84 To investigate $P s g$ virulence factors, we constructed a bacterial mutant library based on 85 transposon insertion in $P s g$, and screened for mutants with less or no chlorosis on soybean leaves 86 after syringe-inoculation. We successfully identified several virulence factors including COR, 87 T3Es, and AlgU. Expression profiles revealed that AlgU promotes virulence in host plants not 88 only by up-regulation of COR-related gene expression. We also showed that alg $U$ mutant showed 89 reduced COR production and biofilm formation compared to WT. Our results provide evidence 90 that AlgU plays a critical role in promoting Psg pathogenesis.

91

\section{Materials \& Methods}

93

94

95

96

97

98

99

100

101

102

103

104

105

106

107

108

109

110

111

112

113

114

115

116

117

118

119

\section{Bacterial strains, plasmids, and growth conditions}

The bacterial strains and plasmids used in this study are listed in Table 1. Pseudomonas strains were routinely cultured on King's B (KB; King et al., 1954) medium or mannitol-glutamate (MG; Keane et al., 1970) medium at $28^{\circ} \mathrm{C}$. Escherichia coli (E. coli) cultures were grown on LuriaBertani (LB; Sambrook et al. 1989) medium at $37^{\circ} \mathrm{C}$. The bacterial cell densities at $600 \mathrm{~nm}\left(\mathrm{OD}_{600}\right)$ were measured using a Biowave CO8000 Cell Density Meter (Funakoshi, Tokyo, Japan) as described in Sakata et al., (2021).

\section{Bacterial in vitro Growth Measurements}

Wild-type, the $\operatorname{alg} U$ mutant, and the $\operatorname{alg} U$-complemented strain were grown at $28^{\circ} \mathrm{C}$ on LB medium. The bacterial suspensions were standardized to an $\mathrm{OD}_{600}$ of 0.05 with $\mathrm{LB}$, and bacterial growth was measured at $\mathrm{OD}_{600}$ for 6,9 , and $12 \mathrm{~h}$.

\section{Plant material and inoculation procedures}

Soybean plants (Glycine max), cultivar "Enrei", were grown in a growth chamber at $22^{\circ} \mathrm{C}$, with approximately $60 \%$ humidity, and a supplementary light intensity of $200-350 \mu \mathrm{mol} /\left(\mathrm{m}^{2} \mathrm{sec}\right)$ for a $14 \mathrm{~h}$ photoperiod. All soybean plants used for virulence studies were three or four-weeksold.

Psg carrying $\operatorname{Tn} 5$ transposon was syringe-infiltrated into soybean leaves at an $\mathrm{OD}_{600}$ of 0.1 $\left(5 \times 10^{7} \mathrm{CFU} / \mathrm{ml}\right)$ containing $0.02 \%$ Silwet L-77 (OSi Specialties Inc., Danbury, CT, USA). The disease symptoms were fully developed at 6 days post inoculation (dpi) (Fig. 1A). The mutants which showed different disease symptoms or virulence reduction in comparison to Psg WT were selected.

For spray inoculation, bacterial suspensions were applied to observe disease symptoms on whole soybean plants as described previously (Uppalapati et al. 2007). Plants were sprayed with a bacterial suspension at an $\mathrm{OD}_{600}$ of $0.2\left(1 \times 10^{8} \mathrm{CFU} / \mathrm{ml}\right)$ in sterile distilled water containing $0.025 \%$ Silwet L-77 until runoff. After inoculation, plants were transferred to growth chambers at 
120

121

122

123

124

125

126

127

128

129

130

131

132

133

134

135

136

137

138

139

140

141

142

143

144

145

146

147

148

149

150

151

152

153

154

155

156

157

158

159

$28^{\circ} \mathrm{C}$ with approximately 90 to $100 \%$ humidity for $24 \mathrm{~h}$ in the dark before maintaining plants at approximately $70 \%$ humidity.

For syringe inoculation, bacteria were suspended at a final concentration at an $\mathrm{OD}_{600}$ of 0.1 $\left(5 \times 10^{7} \mathrm{CFU} / \mathrm{ml}\right), 0.01\left(5 \times 10^{6} \mathrm{CFU} / \mathrm{ml}\right)$, and $0.001\left(5 \times 10^{5} \mathrm{CFU} / \mathrm{ml}\right)$, and infiltrated with a $1-\mathrm{ml}$ blunt syringe into leaves. The plants were then incubated at $70-80 \%$ humidity for the rest of the experimental period. Leaves were removed and photographed at $5 \mathrm{dpi}$.

To measure bacterial growth in soybean leaves after spray inoculation, individual second leaf pairs were selected at $6 \mathrm{dpi}$, weighed and surface-sterilized in $5 \% \mathrm{H}_{2} \mathrm{O}_{2}$ for $3 \mathrm{~min}$, and then rinsed three times with sterile water. The leaves were then homogenized, and appropriate dilutions were plated on KB medium containing the appropriate antibiotics. The bacterial colony forming units (CFU) were normalized as CFU/g using the total inoculated leaf mass. The population at 0 dpi was estimated using leaves harvested $1 \mathrm{~h}$ post inoculation (hpi) without surface-sterilization. For syringe-inoculation, leaf discs were harvested using a $3.5 \mathrm{~mm}$-diameter cork-borer from syringeinfiltrated leaf zone. The leaves were then homogenized, and appropriate dilutions were plated on KB medium containing the appropriate antibiotics. The bacterial colony forming units (CFU) were normalized as $\mathrm{CFU} / \mathrm{cm}^{2}$ using the leaf square meters. The bacterial populations were evaluated in at least three independent experiments.

\section{Transposon-mediated mutagenesis and identification of mutated genes}

Transposon-mediated mutagenesis was carried out, as described previously (Sakata et al. 2019). Briefly, pBSLC1 (Sawada et al., 2018) carrying mini-Tn5 transposon were transferred into

Psg to build a mutant library. We developed more than 1,000 individual Psg mutant lines. After the inoculation assay, we identified the mutated genes by rescuing the transposon insertion sites into an E. coli plasmid and sequencing (Sakata et al., 2019).

\section{Complementation of the alg $U$ mutant}

The algU-complemented strain was constructed as described in Ishiga et al., (2018). Briefly, the pDSKG vector was made from pDSK519 vector (Keen et al., 1988) by replacing kanamycin cassette to gentamycin. The $\operatorname{alg} U$ and promoter region were transferred into the pDSKG vector (Keen et al., 1988) to generate pDSKG-alg $U$. The pDSKG-alg $U$ construct was introduced into the $\operatorname{alg} U$ mutant by electrophoresis to generate the complemented strain.

\section{Real-time quantitative RT-PCR}

For Psg gene expression profiles, data were collected as previously described in Sakata et al., (2021). Specifically, bacteria were grown in HS medium optimized for COR production (HSC; Palmer and Bender, 1993) for 3 and $48 \mathrm{~h}$. Bacterial RNA was extracted using the ReliaPrep RNA Cell Miniprep System Kit (Promega, WI, USA) according to the manufacture's protocol. Two micrograms of total RNA were treated with gDNA Remover (TOYOBO, Osaka, Japan) to eliminate genomic DNA, and the DNase-treated RNA was reverse transcribed using the ReverTra Ace qPCR RT Master Mix (TOYOBO). The cDNA (1:10) was then used for RT-qPCR using the primers shown in Supplementary Table S1 with THUNDERBIRD SYBR qPCR Mix (TOYOBO) 
160

161

162

163

164

165

166

167

168

169

170

171

172

173

174

175

176

177

178

179

180

181

182

183

184

185

186

187

188

189

190

191

192

193

194

195

196

197

198

199

on a Thermal Cycler Dice Real Time System (TaKaRa). Psg outer membrane lipoprotein I (oprI) was used to normalize gene expression.

\section{COR quantification by HPLC}

$P s g$ WT, the $\operatorname{alg} U$ mutant, and the $\operatorname{alg} U$-complemented strain were cultured in HSC for 7 days. Culture supernatant was obtained by centrifugation $(12,000 \times \mathrm{g}$ for $5 \mathrm{~min})$. Cell pellets were dried at $65^{\circ} \mathrm{C}$ and weighed. The $500 \mu \mathrm{l}$ of supernatants were extracted twice with $500 \mu \mathrm{l}$ of ethyl acetate and $25 \mu \mathrm{l}$ of $\mathrm{HCl}$, and the organic phase was transferred to a new microcentrifuge tube. The sample was dried by centrifugal evaporator at $55^{\circ} \mathrm{C}$, and the dried sample was dissolved with $0.05 \%$ trifluoroacetic acid (TFA)/acetonitrile $(9: 1, \mathrm{v} / \mathrm{v})$. The culture supernatant was analyzed by HPLC with a Shimadzu LC20A system equipped with a Symmetry C8 column $(4.6 \times 250 \mathrm{~mm}$; Waters Corporation, MA, USA) as described previously (Sakata et al. 2021).

\section{Hypertrophy-inducing activity assay on potato tuber tissue}

Potato tubers were cut from the central tuber portion to ensure samples of high uniformity. After washing in tap water for $5 \mathrm{~min}$, each disc was washed with sterile distilled water several times. Potato tuber discs were inoculated using toothpicks by placing the tip in Psg WT, CORdefective mutants ( $c f a 6$ and $c m a A$ ), the $\operatorname{alg} U$ mutant, and the $\operatorname{alg} U$-complemented strain on a $\mathrm{KB}$ medium plate, and then placing the toothpick on the potato tuber disc. The discs were then placed at $23^{\circ} \mathrm{C}$ incubator (darkness) for 5 days. Photographs were taken at 5 dpi.

\section{Biofilm formation assay}

Biofilm formation was assayed as described previously (Shao et al., 2019). Briefly, the bacterial strains were incubated overnight in LB broth and resuspended in fresh LB broth to an $\mathrm{OD}_{600}$ of 0.1 . Bacterial suspensions $(120 \mu \mathrm{l})$ were put into 96 -well plates and incubated at $28^{\circ} \mathrm{C}$ for $24,48,72$, and $96 \mathrm{~h}$. The bacterial solutions were discarded and washed three times with distilled water. The biofilm forming bacteria were treated with $150 \mu 1$ of $0.1 \%$ crystal violet (CV; Fujifilm, Tokyo, Japan) for 20 min without shaking. The dye was discarded and washed twice with distilled water. The plate was dried completely, subsequently the biofilm was eluted with $150 \mu \mathrm{l}$ of $100 \%$ ethanol, and the CV were dissolved completely. Finally, the eluted biofilm sample's absorbance was measured at $\mathrm{OD}_{595}$.

\section{Results}

\section{Identification and characterization of reduced virulence mutants}

To identify $P s g$ virulence genes, we screened 1,000 transposon insertion mutants for reduced disease symptoms on soybean leaves using the syringe-infiltration method. Disease symptoms caused by Psg WT showed a small water-soaked lesion surrounded by regions of chlorosis (Fig. 1A). A total of 28 mutants showed no or less chlorosis at 6 dpi (Fig. 1B). Seventeen mutants out of 28 had transposon insertions in genes encoding COR biosynthesis-related genes (Table 1). Soybean leaves inoculated with COR biosynthesis mutants (VTD29, VTE13, VTI15, and VTR4), 
200 the $\operatorname{alg} U$ mutant (VTO41), and an unknown-function mutant (VTF6) showed no chlorosis (Fig. 201 1B).

202

203

204

205

206

207

208

209

210

211

212

213

214

215

216

217

218

219

220

221

222

223

224

225

226

227

228

229

230

231

232

233

234

235

236

237

238

239

\section{Reduced disease symptoms and bacterial growth in soybean}

We identified the 28 mutants which showed reduced disease symptoms compared to Psg WT by syringe-inoculation (Fig. 1B). We further investigated whether these mutants also showed reduced virulence via spray-inoculation, and selected 2 mutants related to COR biosynthesis ( $c m a A$ and $c f a 6$ ), and others. Soybean leaves inoculated with all mutants showed significantly reduced bacterial populations than those of $P s g$ WT (Fig. 2A). Among all mutants, the $a \lg U$ mutant (VTO41) showed dramatically reduced bacterial populations and disease symptoms at 6 dpi (Figs. 2A and $2 \mathrm{~B})$. To confirm whether the altered $\operatorname{alg} U$ mutant phenotype originates from a corresponding mutation, an alg $U$-complemented strain was generated. $P s g \mathrm{WT}$ and the $\operatorname{alg} U$-complemented strain showed the same bacterial population levels as well as disease symptom development in soybean (Supplementary Figs. S1A and S1B). We also confirmed that $\operatorname{alg} U$ is apparently dispensable for $P s g$ growth in rich LB medium, since no growth difference was observed among WT, alg $U$ mutant, and $\operatorname{alg} U$-complemented strain (Supplementary Fig. S2).

To further investigate the algU contribution to $P s g$ virulence, we conducted syringe infiltration with WT, $\operatorname{alg} U$ mutant, and $\operatorname{alg} U$-complemented strain. As a result, the $\operatorname{alg} U$ mutant showed reduced symptoms and bacterial populations at all inoculum levels we tested (Figs. 3A-3F). Taken together, these results indicate that $\mathrm{AlgU}$ contributes to growth both on leaf surface and in apoplast, and to causing disease.

\section{AlgU regulates the expression of $P$ sg virulence genes in HSC medium}

Pst DC3000 AlgU positively regulates virulence gene transcription (Markel et al. 2016; Ishiga et al. 2018). To investigate whether Psg AlgU also regulates virulence genes, we analyzed virulence gene expression profiles in HSC medium. COR biosynthesis-related genes including $\mathrm{cmaA}$ and $c o r R$, in the $\operatorname{alg} U$ mutant showed reduced expression at $48 \mathrm{~h}$ after incubation (Figs. 4A and 4C). Moreover, $h r p L$, encoding HrpL (an alternative sigma factor recognizing the $h r p$ box in the promoter of T3SS genes), also showed significantly less expression in the alg $U$ mutant at both 3 and $48 \mathrm{~h}$ after incubation compared to Psg WT (Fig. 4D). These results indicate that AlgU positively regulates COR biosynthesis-related genes and $h r p L$.

To investigate whether AlgU can coordinate gene expression involved in Psg motility, we determined the expression profile of $f l i C$ (encoding flagellin, relating to flagellar mobility). At $3 \mathrm{~h}$ after incubation, there was no difference in the flagellar-encoding gene expression between the alg $U$ mutant and $P_{s g} \mathrm{WT}$. However, after $48 \mathrm{~h}$ incubation, relative $f l i C$ expression was greater in the alg $U$ mutant compared to Psg WT (Fig. 4E). Additionally, $\operatorname{alg} D$ expression was down regulated in the $\operatorname{alg} U$ mutant (Fig. $4 \mathrm{~F}$ ), indicating that $\mathrm{AlgU}$ positively regulates alginate biosynthesis-related genes.

\section{AlgU contributes to COR biosynthesis and biofilm formation in Psg}


240

241

242

243

244

245

246

247

248

249

250

251

252

253

254

255

256

257

258

259

260

261

262

263

264

265

266

267

268

269

270

271

272

273

274

275

276

277

278

279

We demonstrated that COR biosynthesis-related genes in the $\operatorname{alg} U$ mutant showed reduced expression in HSC medium (Figs. 4A-4D). To investigate whether AlgU contributes to COR production, we first conducted a hypertrophy-inducting activity test on potato tuber tissues for COR detection (Sakai et al., 1979; Völksch et al., 1989). Potato tuber tissues inoculated with Psg WT showed hypertrophy response, but those inoculated with COR-defective mutants ( $\mathrm{cmaA}$ and $c f a 6$ ) showed no response (Fig. 5A). The $\operatorname{alg} U$ mutant-inoculated potato tuber tissues showed less hypertrophy response compared to those inoculated with $P s g$ WT and the reduction was restored in the algU-complemented strain (Fig. 5A). Furthermore, we also quantified COR production by using HPLC. Psg WT produced around $90 \mathrm{ng} / \mathrm{g}$ of COR in HSC medium (Fig. 5B). However, the $\operatorname{alg} U$ mutant produced only around one third as much COR compared to Psg WT (Fig. 5B). We also confirmed that the alg $U$-complemented strain recovered COR production more than WT (Fig. 5B). Taken together, these results suggest that AlgU contributes to COR biosynthesis in Psg.

Since we also demonstrated that alginate biosynthesis-related genes $\operatorname{alg} D$ showed reduced expression in $\operatorname{alg} U$ mutant (Fig. 4F), we next investigated the biofilm formation ability in Psg WT and the $\operatorname{alg} U$ mutant. The $\operatorname{alg} U$ mutant showed a reduction in biofilm formation at 24, 48, and 72 hpi (Fig. 6). These results suggest that AlgU also contributes to biofilm formation in Psg.

\section{Discussion}

We attempted to identify $P s g$ virulence factors that are crucial in soybean pathogenicity. We screened 1,000 Psg mutants by syringe-infiltration and identified 28 mutants with reduced virulence (Fig. 1B). Several important virulence factors contribute to Psg virulence including COR, the T3SS, and AlgU (Table 1). Sigma factor AlgU regulates not only algD, but also other virulence genes including $h r p L$ and COR (Figs. 4A-4F). Our study provides new insights into $\mathrm{AlgU}$ function as a global regulatory hub for Psg pathogenicity by regulating the expression of multiple virulence genes.

Our screening identified that 17 out of 28 reduced virulence mutants were related to COR biosynthesis genes. These COR biosynthesis mutants were mostly disrupted by Tn 5 on the $c f a$ and cma operons (Table 1). The $c f a$ and $c m a$ operons encode enzymes related to CFA and CMA biosynthesis, respectively, the two elements that are ligated together to form COR (Bender et al., 1999). Together, these results indicate that COR is an important Psg virulence factor.

The $\operatorname{alg} U$ mutant showed reduced virulence in plants both spray- and syringe-inoculated (Figs. 2; Supplementary Fig. S1; Figs. 3), indicating that AlgU contributes to Psg multiplication both on leaf surface and in apoplast, and causing disease. Our results indicate that AlgU regulate several virulence factors. Firstly, gene expression related to COR biosynthesis, such as $\mathrm{cmaA}$ and corR (but not $c f l$ ) were suppressed in the $\operatorname{alg} U$ mutant (Figs. 4A-4C). Moreover, COR production in the $\operatorname{alg} U$ mutant also less than that of Psg WT (Figs. 5A and 5B), suggesting that AlgU contributes to COR production in Psg. Consistent with our results, Ishiga et al. (2018) demonstrated that gene expression related to COR biosynthesis was suppressed during Pst DC3000 algU mutant infection. Furthermore, AlgU also contributes to Pst DC3000 virulence by regulating COR production to overcome stomatal-based defense (Ishiga et al., 2018). Together, 
280

281

282

283

284

285

286

287

288

289

290

291

292

293

294

295

296

297

298

299

300

301

302

303

304

305

306

307

308

309

310

311

312

313

314

315

316

317

318

319

these results suggest that $\mathrm{AlgU}$ suppresses stomatal-based defense in the early Psg infection stage with soybean plants. Moreover, COR contributes to virulence by overcoming apoplastic defense as well as stomatal-based defense in Pcal (Sakata et al., 2021). Further study on COR contribution in Psg virulence will be needed to understand AlgU-mediated COR regulation.

Secondary, the $\operatorname{alg} D$ expression profile in the $\operatorname{alg} U$ mutant was significantly reduced in comparison with Psg WT, indicating that $\mathrm{AlgU}$ is important in regulating alginate biosynthesis gene expression (Fig. 4F). This result was consistent with a previous report in Pst DC3000 (Ishiga et al., 2018), in which $\operatorname{alg} D$ expression was significantly suppressed in an $\operatorname{alg} U$ mutant. Further, alginate plays a crucial role in epiphytic fitness and survival, and contributes to $P$. syringae virulence (Yu et al., 1999). Alginate is one of the exopolysaccharides (EPSs), which are the major components of biofilms, in Psg (Osman et al., 1986; Sutherland, 2001). We demonstrated that biofilm formation was significantly decreased in the alg $U$ mutant compared with Psg WT (Fig. 6). Psg PG4180 AlgU is important in virulence and bacterial growth in host plants, but it is not dependent on alginate production (Schenk et al., 2008; Yu et al., 2014). Additionally, AlgU, but not AlgD plays a crucial role in Pst DC3000 virulence (Markel et al. 2016). Together, it is tempting to speculate that alginate function in virulence differs in each $P$. syringae pathovar. Thus, further study is needed to understand AlgU regulating genes involved in biofilm formation and alginate function in $P s g$ virulence.

Thirdly, expression profiles also revealed $h r p L$ transcripts were suppressed in the $\operatorname{alg} U$ mutant compared with Psg WT (Fig. 4D). Pst DC3000 AlgU functions to regulate hrpL expression (Ishiga et al., 2018). Markel et al., (2016) also demonstrated that AlgU plays an important role in virulence by regulating the expression of T3Es and $h r p L$. In P. syringae, both the T3SS and T3Es genes are in turn encoded by the hrp gene cluster, while the sigma factor HrpL directly regulates both $h r c$ and hop genes (Lam et al., 2014). Although many studies were caried out to elucidate the functions and mode of actions of the T3SS and its T3Es, AlgU regulation on the T3SS system is still unknown in $P$. syringae infection processes. Therefore, further precise characterization of AlgU-mediated T3SS regulation will be needed to understand global gene expression networks during Psg infection.

Lastly, $f l i C$ transcripts in the algU mutant were increased compared with those of $P s g$ WT (Fig. 4E). In Pst DC3000, AlgU not only downregulates flagellar and chemotaxis genes in vitro (Markel et al., 2016), but also negatively regulates $f l i C$ expression during infection (Bao et al., 2020). $f l i C$ encodes the flagellin protein including the flg22 epitope which triggers PTI (Felix et al., 1999; Zipfel et al., 2004; Parys et al., 2021; Colaianni et al., 2021). Recent studies reported the important role of $\mathrm{AlgU}$ in de-flagellation during the $P$. syringae-plant interaction to reduce PTI activation, and promote bacterial fitness in its host (Bao et al., 2020). Likewise, AlgU also plays an important role in de-flagellation of $P$. syringae pv. maculicula ES4236, in which transposon inactivation of $\mathrm{AlgW}$ led to decreased $\mathrm{AlgU}$ activity and increased the flagella expression, as well as reduced bacterial growth in planta (Schreiber and Desveaux, 2011). Therefore, it is tempting to speculate that high levels of flagellin protein production in the $\operatorname{alg} U$ mutant activate PTI. 
320

321

322

323

324

325

326

327

328

329

330

331

332

333

334

335

336

337

338

339

340

341

342

343

344

345

346

347

348

349

350

351

352

353

354

355

356

357

358

\section{Conclusions}

Our findings indicate that multiple virulence factors regulated by AlgU, including COR biosynthesis, biofilm formation, and T3SS, contributes to $P s g$ virulence in soybean. Our findings help to expand understanding of AlgU roles in Psg virulence. Further studies on AlgU regulated mechanisms will be needed to fully understand $P s g$ virulence.

\section{Acknowledgements}

We thank Dr. Christina Baker for editing the manuscript. Psg WT were given from the NARO Genebank, Ibaraki, Japan.

\section{References}

Bao Z, Wei HL, Ma X, Swingle B (2020) Pseudomonas syringae AlgU downregulates flagellin gene expression, helping evade plant immunity. J Bacteriol 202:e00418-19

Bender CL (1999) Chlorosis-inducing phytotoxins produced by Pseudomonas syringae. Eur J Plant Pathol 105:1-12

Bender CL, Young SA, Mitchell RE (1991) Conservation of plasmid DNA sequences in coronatine-producing pathovars of Pseudomonas syringae. Appl Environ Microbiol 57:993999

Bender CL, Srone HE, Sims JJ, Cooksey DA (1987) Reduced pathogen fitness of Pseudomonas syringae pv. tomato Tn5 mutants defective in coronatine production. Physiol Mol Plant Pathol 30:237-283

Brooks DM, Bender CL, Kunkel BN (2005) The Pseudomonas syringae phytotoxin coronatine promotes virulence by overcoming salicylic acid-dependent defenses in Arabidopsis thaliana. Mol Plant Pathol 6:629-639

Brooks DM, Hernández-Guzmán G, Kloek AP, Alarcón-Chaidez F, Sreedharan A, Rangaswamy V, Peñaloza-Vázquez A, Bender CL, Kunkel BN (2004) Identification and characterization of a well-defined series of coronatine biosynthetic mutants of Pseudomonas syringae pv. tomato DC3000. Mol Plant Microbe Interact 17:162-174

Budde IP, Ullrich MS (2000) Interactions of Pseudomonas syringae pv. glycinea with host and nonhost plants in relation to temperature and phytotoxin synthesis. Mol Plant Microbe Interact 13:951-61

Colaianni NR, Parys K, Lee H-S, Conway JM, Kim NH, Edelbacher N, Mucyn TS, Madalinski M, Law TF, Jones CD, Belkhadir Y, Dangl JL (2021) A complex immune response to flagellin epitope variation in commensal communities. Cell Host Microbe 29:635-649.e9

Felix G, Duran JD, Volko S, Boller T (1999) Plants have a sensitive perception system for the most conserved domain of bacterial flagellin. Plant J 18:265-276

Haefelet DM, Lindow SE (1987) Flagellar motility confers epiphytic fitness advantages upon Pseudomonas syringae. Appl Environ Microbiol 53:2528-2533 
359

360

361

362

363

364

365

366

367

368

369

370

371

372

373

374

375

376

377

378

379

380

381

382

383

384

385

386

387

388

389

390

391

392

393

394

395

396

397

398

399

Hoitink H, and Sinden S (1970) Partial purification and properties of chlorosis inducing toxins of Pseudomonas phaseolicola and Pseudomonas glycinea. Phytopathology 60:1236-1237

Ignjatov M, Milošević M, Nikolić Z, Vujaković M, Petrović D (2007) Characterization of Pseudomonas savastanoi pv. glycinea isolates from Vojvodina. The Polish Phytopathol Soci 45:43-54

Ishiga T, Ishiga Y, Betsuyaku S, Nomura N (2018) AlgU contributes to the virulence of Pseudomonas syringae pv. tomato DC3000 by regulating production of the phytotoxin coronatine. J Gen Plant Pathol 84:189-201

Keane P, Kerr A, New P (1970) Crown gall of stone fruit II. Identification and nomenclature of Agrobacterium isolates. Aust J Biol Sci 23:585-596

Keen NT, Tamaki S, Kobayashi D, Trollinger D (1988) Improved broad-host-range plasmids for DNA cloning in gram-negative bacteria. Gene 70:191-197

King EO, Ward MK, Raney DE (1954) Two simple media for the demonstration of pyocyanin and fluorescin. J Lab Clin Med 44:301-307

Kloek AP, Verbsky ML, Sharma SB, Schoelz JE, Vogel J, Klessig DF, Kunkel BN (2001) Resistance to Pseudomonas syringae conferred by an Arabidopsis thaliana coronatineinsensitive (coil) mutation occurs through two distinct mechanisms. Plant J 26:509-522

Lam HN, Chakravarthy S, Wei HL, Nguyen BH, Stodghill PV, Collmer A, Swingle BM, Cartinhour SW (2014) Global analysis of the HrpL regulon in the plant pathogen Pseudomonas syringae pv. tomato DC3000 reveals new regulon members with diverse functions. PLoS One 9:e106115

Markel E, Stodghill P, Bao Z, Myers C, Swingle B (2016) AlgU controls expression of virulence genes in Pseudomonas syringae pv. tomato DC3000. J Bacteriol 198:2330-2344

Melotto M, Underwood W, Koczan J, Nomura K, He SY (2006) Plant stomata function in innate immunity against bacterial invasion. Cell 126:969-980

Osman SF, Fett WF, Fishman ML (1986) Exopolysaccharides of the phytopathogen Pseudomonas syringae pv. glycinea. J Bacteriol 166:66-71

Palmer DA, Bender CL (1993) Effects of environmental and nutritional factors on production of the polyketide phytotoxin coronatine by Pseudomonas syringae pv. glycinea. Appl Environ Microbiol 59:1619-1626

Parys K, Colaianni NR, Lee H-S, Hohmann U, Edelbacher N, Trgovcevic A, Blahovska Z, Lee D, Mechtler A, Muhari-Portik Z, Madalinski M, Schandry N, Rodríguez-Arévalo I, Becker C, Sonnleitner E, Korte A, Bläsi U, Geldner N, Hothorn M, Jones CD, Dangl JL, Belkhadir Y (2021) Signatures of antagonistic pleiotropy in a bacterial flagellin epitope. Cell host \& microbe.

Peñaloza-Vázquez A, Preston GM, Collmer A, Bender CL (2000). Regulatory interactions between the Hrp type III protein secretion system and coronatine biosynthesis in Pseudomonas syringae pv. tomato DC3000. Microbiology 146:2447-2456

Qi M, Wang D, Bradley CA, Zhao Y (2011) Genome sequence analyses of Pseudomonas savastanoi pv. glycinea and subtractive hybridization-based comparative genomics with nine Pseudomonads. PLoS One 6:e16451 
400

401

402

403

404

405

406

407

408

409

410

411

412

413

414

415

416

417

418

419

420

421

422

423

424

425

426

427

428

429

430

431

432

433

434

435

436

437

438

Sakai R, Nishiyama K, Ichihara A, Shiraishi K, Sakamura S (1979) Studies on the mechanism of physiological activity of coronatine. Jpn J Phytopathol 45:645-653

Sakata N, Ishiga T, Saito H, Nguyen VT, Ishiga Y (2019) Transposon mutagenesis reveals Pseudomonas cannabina pv. alisalensis optimizes its virulence factors for pathogenicity on different hosts. PeerJ 7:e7698

Sakata N, Ishiga T, Masuo S, Hashimoto Y, Ishiga Y (2021) Coronatine contributes to Pseudomonas cannabina pv. alisalensis virulence by overcoming both stomatal and apoplastic defenses in dicot and monocot plants. Mol Plant Microbe Interact doi: 10.1094/MPMI-09-20-0261-R

Sambrook J, Fritsch E, Maniatis T (1989) Molecular cloning: a laboratory manual, 2nd edition. Cold Spring Harbor Laboratory, Cold Spring Harbor, New York

Sawada T, Eguchi M, Asaki S, Kashiwagi R, Shimomura K, Taguchi F, Matsui H, Yamamoto M, Noutoshi Y, Toyoda K, Ichinose Y (2018) MexEF-OprN multidrug efflux pump transporter negatively controls $\mathrm{N}$-acyl-homoserine lactone accumulation in Pseudomonas syringae pv. tabaci 6605. Mol Genet Genom 293:907-917

Schäfer A, Tauch A, Jäger W, Kalinowski J, Thierbach G, Pühler A. (1994) Small mobilizable multi-purpose cloning vectors derived from the Escherichia coli plasmids pK18 and pK19: selection of defined deletions in the chromosome of Corynebacterium glutamicum. Gene 145:69-73

Schenk A, Weingart H, Ullrich MS (2008) The alternative sigma factor AlgT, but not alginate synthesis, promotes in planta multiplication of Pseudomonas syringae pv. glycinea. Microbiology 154:413-421

Schenk A, Berger M, Keith LM, Bender CL, Muskhelishvili G, Ullrich MS (2006). The algT gene of Pseudomonas syringae pv. glycinea and new insights into the transcriptional organization of the algT-muc gene cluster. J Bacteriol 188:8013-8021

Schreiber KJ, Desveaux D (2011) AlgW regulates multiple Pseudomonas syringae virulence strategies. Mol Microbiol 80:364-377

Shao X, Xie Y, Zhang Y, Deng X (2019) Biofilm formation assay in Pseudomonas syringae. Bio-protocol 9:e3237-e3237

Sutherland, I. (2001) Biofilm exopolysaccharides: a strong and sticky framework. Microbiology $147: 3-9$

Ullrich M, Bereswill S, Volksch B, Fritsche W, Geider K (1993) Molecular characterization of field isolates of Pseudomonas syringae pv. glycinea differing in coronatine production. Microbiology 139:1927-1937

Uppalapati SR, Ayoubi P, Weng H, Palmer DA, Mitchell RE, Jones W, Bender CL (2005) The phytotoxin coronatine and methyl jasmonate impact multiple phytohormone pathways in tomato. Plant J 42:201-217

Uppalapati SR, Ishiga Y, Wangdi T, Kunkel BN, Anand A, Mysore KS, Bender CL (2007) The phytotoxin coronatine contributes to pathogen fitness and is required for suppression of 
439 salicylic acid accumulation in tomato inoculated with Pseudomonas syringae pv. tomato DC3000. Mol Plant Microbe Interact 20:955-965

441 Völksch B, Bublitz F, Fritsche W (1989) Coronatine production by Pseudomonas syringae

442 pathovars: screening method and capacity of product formation. J Basic Microbiol 29:463$443 \quad 468$

444 Yu J, Peñaloza-Vázquez A, Chakrabarty AM, Bender CL (1999) Involvement of the 445 exopolysaccharide alginate in the virulence and epiphytic fitness of Pseudomonas syringae 446 pv. syringae. Mol Microbiol 33:712-720

$447 \mathrm{Yu}$ X, Lund SP, Greenwald JW, Records AH, Scott RA, Nettleton D, Lindow SE, Gross DC, 448 Beattie GA (2014) Transcriptional analysis of the global regulatory networks active in 449 Pseudomonas syringae during leaf colonization. mBio 5:e01683-14

450 Zhao Y, Thilmony R, Bender CL, Schaller A, He SY, Howe GA (2003) Virulence systems of $451 \quad$ Pseudomonas syringae pv. tomato promote bacterial speck disease in tomato by targeting the 452 jasmonate signaling pathway. Plant J 36:485-499

453 Zipfel C, Robatzek S, Navarro L, Oakeley EJ, Jones JDG, Felix G, Boller T (2004) Bacterial 454 disease resistance in Arabidopsis through flagellin perception. Nature 428:764-767 


\section{Table $\mathbf{1}$ (on next page)}

Bacterial strains and plasmids used in this study 
Table 1 Bacterial strains and plasmid used in this study

\begin{tabular}{|c|c|c|c|}
\hline $\begin{array}{l}\text { Bacterial strain or } \\
\text { plasmid }\end{array}$ & Locus & Relevant characteristics & Reference or source \\
\hline \multicolumn{4}{|l|}{ E. coli strain } \\
\hline & & $\mathrm{F}-\lambda-\varphi 80 \mathrm{dLacZ} \Delta \mathrm{M} 15 \Delta(\mathrm{lacZYA}-\operatorname{argF}) \mathrm{U} 169$ & \\
\hline $\mathrm{DH} 5 \alpha$ & & $\begin{array}{l}\text { recA1 } \\
\text { endA1 hsdR17 (rK-mK+) supE44 thi-1gyrA }\end{array}$ & Takara, Kyoto, Japan \\
\hline & & relA1 & \\
\hline S17-1 & & $\begin{array}{l}\text { Thi pro hsdR-hsdM + recA [chr::RP4-2- } \\
\text { Tc::Km::Tn7] }\end{array}$ & Schäfer et al. 1994 \\
\hline \multicolumn{4}{|c|}{ P. savastanoi pv. glycinea } \\
\hline Psg & & Psg wild-type & MAFF301684 \\
\hline VTB8 & PsgB076_27735 & $c f a 6:: m T n 5, \mathrm{Nal}^{\mathrm{r}}, \mathrm{Km}^{\mathrm{r}}$ & This study \\
\hline VTC23 & PsgB076_27795 & cmaA::mTn5, $\mathrm{Nal}^{\mathrm{r}}, \mathrm{Km}^{\mathrm{r}}$ & This study \\
\hline VTD16 & PsgB076_27730 & $c f a 5:: m \operatorname{Tn} 5, \mathrm{Nal}^{\mathrm{r}}, \mathrm{Km}^{\mathrm{r}}$ & This study \\
\hline VTD28 & PsgB076_27725 & $c f a 4:: m T n 5, \mathrm{Nal}^{\mathrm{r}}, \mathrm{Km}^{\mathrm{r}}$ & This study \\
\hline VTD29 & PsgB076_27740 & $c f a 7:: m T n 5, \mathrm{Nal}^{\mathrm{r}}, \mathrm{Km}^{\mathrm{r}}$ & This study \\
\hline VTD30 & PsgB076_27720 & $c f a 3:: m T n 5, \mathrm{Nal}^{\mathrm{r}}, \mathrm{Km}^{\mathrm{r}}$ & This study \\
\hline VTE13 & PsgB076_27750 & $c f a 8:: m \operatorname{Tn} 5, \mathrm{Nal}^{\mathrm{r}}, \mathrm{Km}^{\mathrm{r}}$ & This study \\
\hline VTE17 & PsgB076_27740 & $c f a 7:: m \operatorname{Tn} 5, \mathrm{Nal}^{\mathrm{r}}, \mathrm{Km}^{\mathrm{r}}$ & This study \\
\hline VTF3 & PsgB076_27705 & $c f a 2:: m T n 5, \mathrm{Nal}^{\mathrm{r}}, \mathrm{Km}^{\mathrm{r}}$ & This study \\
\hline VTG22 & PsgB076_27735 & $c f a 6:: m T n 5, \mathrm{Nal}^{\mathrm{r}}, \mathrm{Km}^{\mathrm{r}}$ & This study \\
\hline VTG29 & PsgB076_27740 & $c f a 7:: m T n 5, \mathrm{Nal}^{\mathrm{r}}, \mathrm{Km}^{\mathrm{r}}$ & This study \\
\hline VTG41 & PsgB076_27725 & $c f a 5:: m \operatorname{Tn} 5, \mathrm{Nal}^{\mathrm{r}}, \mathrm{Km}^{\mathrm{r}}$ & This study \\
\hline VTH39 & PsgB076_27735 & $c f a 6:: m \operatorname{Tn} 5, \mathrm{Nal}^{\mathrm{r}}, \mathrm{Km}^{\mathrm{r}}$ & This study \\
\hline
\end{tabular}




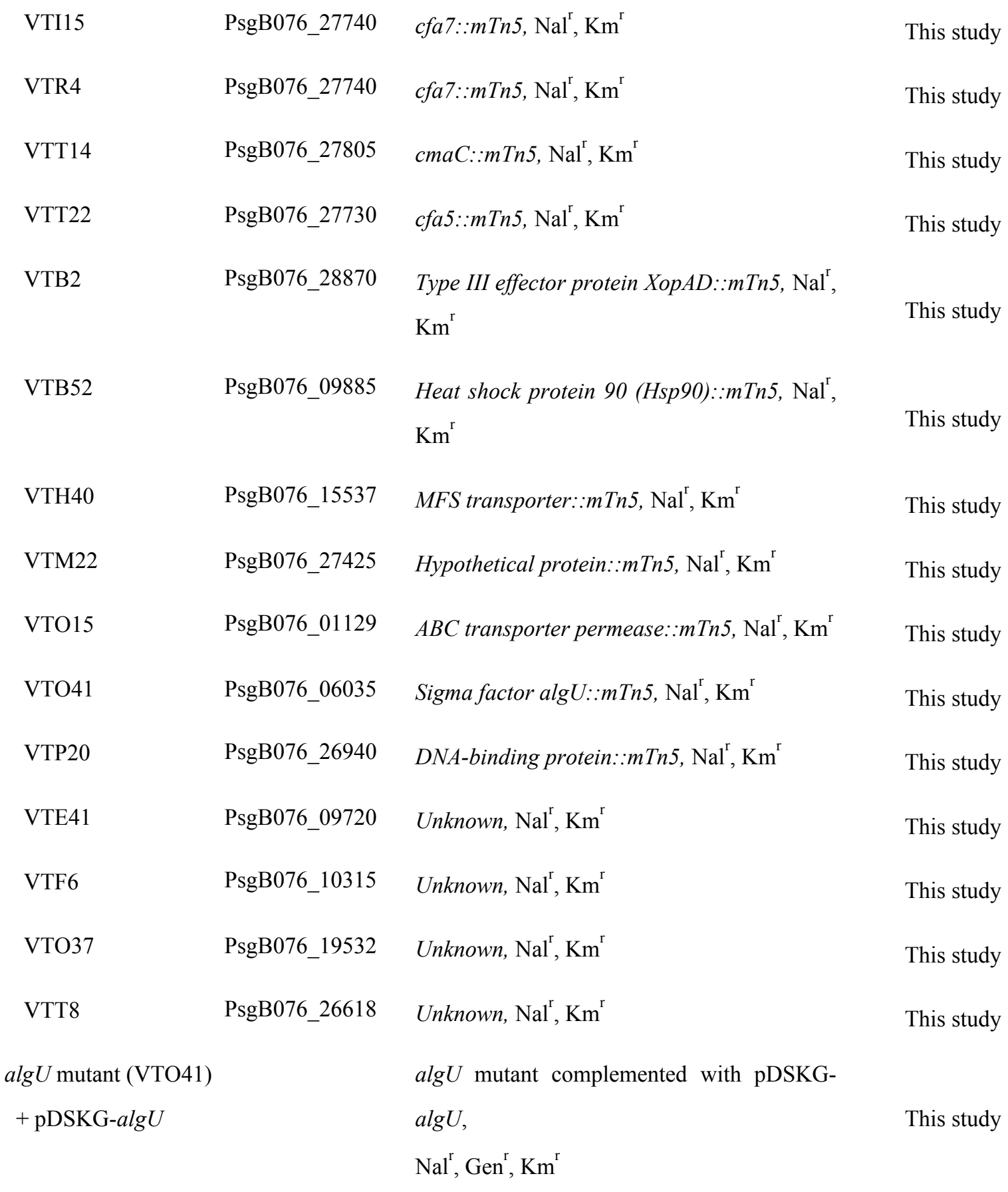

Plasmid

Transposon vector constructed by ligation of

pBSLC1 pBSL118 and pHSG396 at EcoRI site, Amp ${ }^{\mathrm{r}}$,

Sawada et al. 2018

$\mathrm{Km}^{\mathrm{r}}, \mathrm{Cm}^{\mathrm{r}}$

pDSK519

Broad-host-range cloning vector, $\mathrm{Ken}^{\mathrm{r}}$

Keen et al. 1998

pDSKG

Broad-host-range cloning vector, Gen ${ }^{\mathrm{r}}$

This study 
pDSKG-algU

The vector containing alg $U$ gene inserted into pDSK519, Gen ${ }^{\mathrm{r}}$
This study

Notes Amp ${ }^{\mathrm{r}}$ ampicillin resistance, $\mathrm{Cm}^{\mathrm{r}}$ chloramphenicol resistance, Gen ${ }^{\mathrm{r}}$ gentamicin,

$\mathrm{Km}^{\mathrm{r}}$ kanamycin resistance, $\mathrm{Nal}^{\mathrm{r}}$ nalidixic acid resistance.

1 


\section{Figure 1}

Disease symptoms on soybean leaves syringe-inoculated with Pseudomonas savastanoi pv. glycinea (Psg) wild-type (WT) and mutants.

(A) Disease symptoms on soybean leaves syringe-inoculated with $5 \times 10^{7}$ colony forming units (CFU)/ml of the Psg WT at 6 dpi. (B) Disease symptoms on soybean leaves syringeinoculated with $5 \times 10^{7}$ colony forming units (CFU)/ml of the Psg mutants at 6 dpi. Scale bars shows $1 \mathrm{~cm}$. 


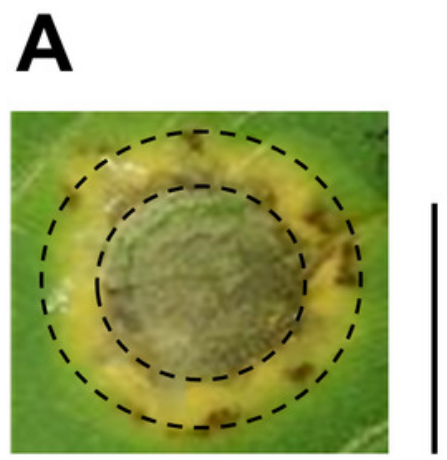

Psg WT

B

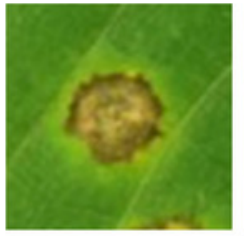

VTB8
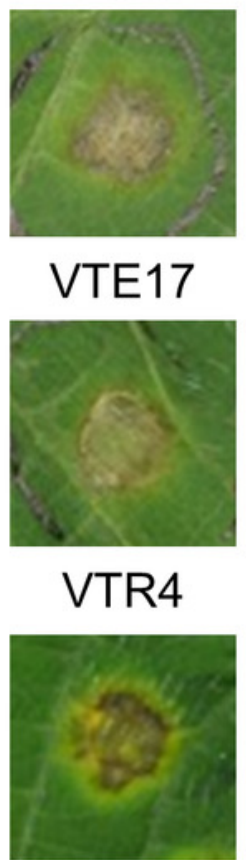

VTO15
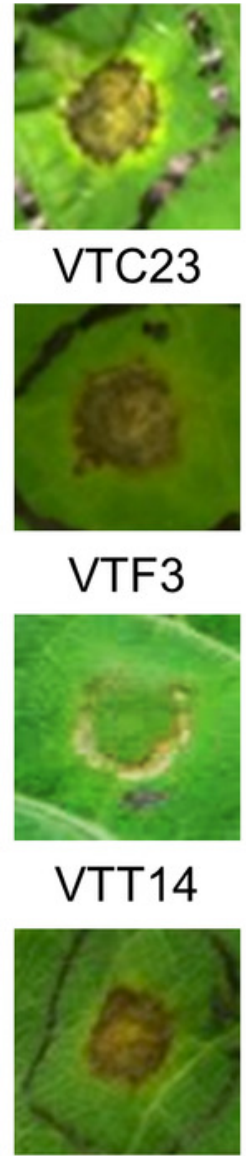

VTO41
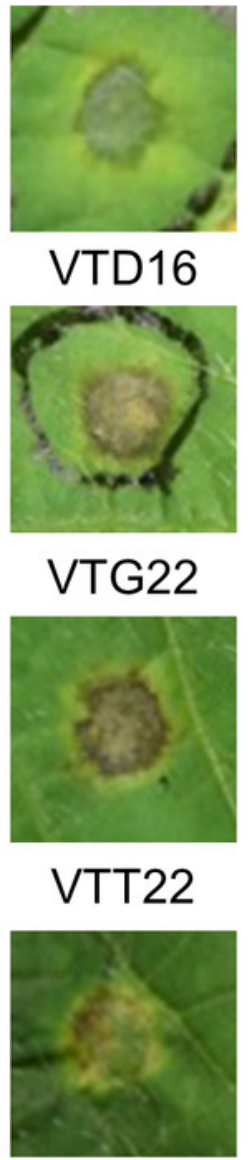

VTP20
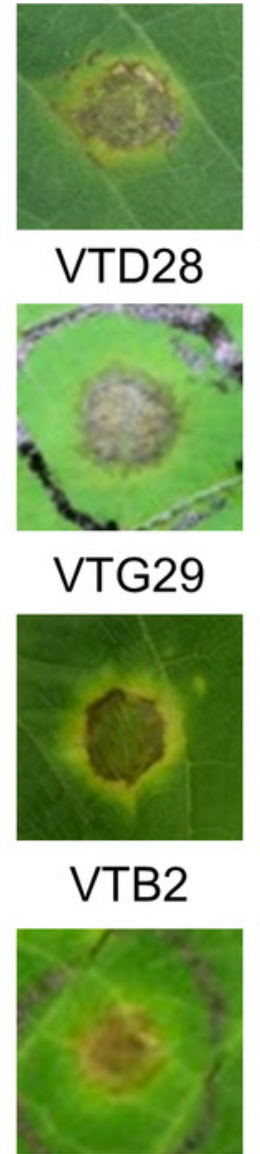

VTE41
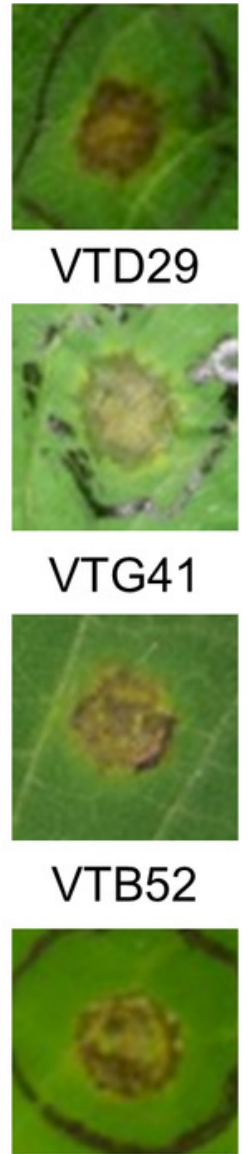

VTF6
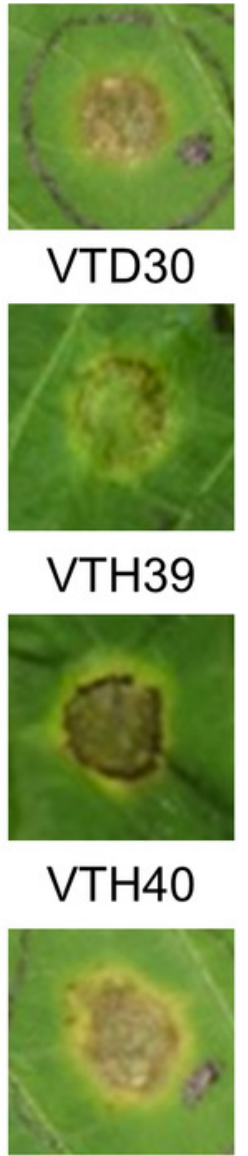

VTO37

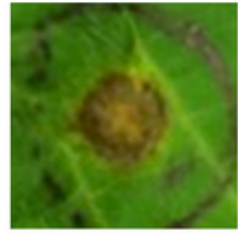

VTE13

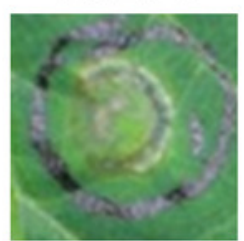

VTI15

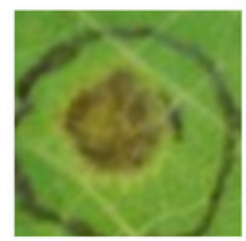

VTM22

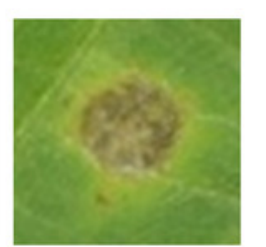

VTT8 


\section{Figure 2}

Bacterial populations and disease symptoms in soybean leaves.

(A) Bacterial populations in leaves spray-inoculated with Pseudomonas savastanoi pv.

glycinea (Psg) wild-type (WT) and mutants $\left(1 \times 10^{8}\right.$ colony forming units (CFU)/ml). Bacterial populations in leaves were estimated at 6 days post inoculation (dpi) by dilution plating on selective medium as described in the methods. Vertical bars indicate standard error for three independent experiments. Asterisks indicate a significant difference from WT in a $t$ test $(* P<$ $0.05 ; * * P<0.01)$. (B) Disease symptoms in leaves spray-inoculated with the Psg WT and the algU mutant $\left(1 \times 10^{8}\right.$ colony forming units $\left.(\mathrm{CFU}) / \mathrm{ml}\right)$ at $6 \mathrm{dpi}$.

A

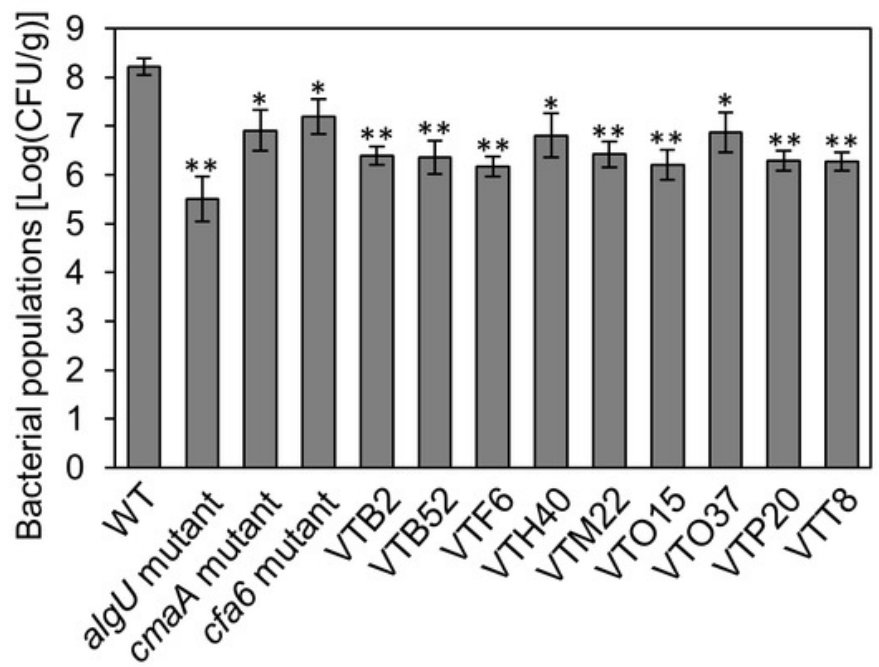

B

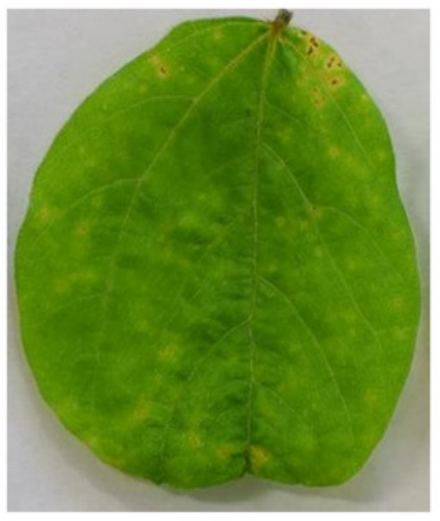

WT

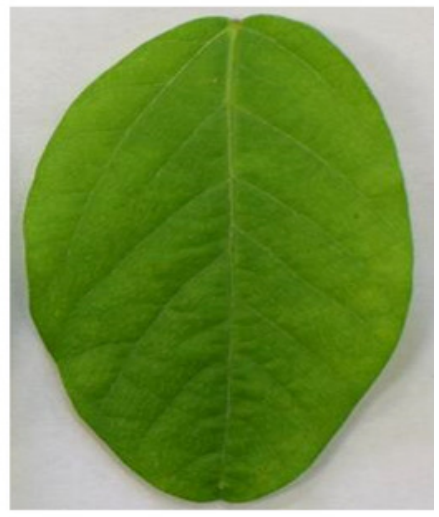

algU mutant 


\section{Figure 3}

Disease symptoms and bacterial populations in soybean leaves after syringe inoculation.

Disease symptom and bacterial populations in leaves syringe-inoculated with Pseudomonas syringae pv. glycinea (Psg) wild-type (WT), the algU mutant, and the algU-complemented strain at $5 \times 10^{7}$ colony forming units (CFU)/ml (A, B), $5 \times 10^{6} \mathrm{CFU} / \mathrm{ml}(\mathrm{C}, \mathrm{D})$, and $5 \times 10^{5}$ $\mathrm{CFU} / \mathrm{ml}(\mathrm{E}, \mathrm{F})$, respectively. Photographs were taken at 5 days post inoculation (dpi). Scale bars shows $1 \mathrm{~cm}$. Bacterial populations in leaves were estimated at 5 dpi by dilution plating on selective medium as described in the methods. Vertical bars indicate standard error for three independent experiments. The different letters indicate significant statistical differences $(P<0.05$, Turkey's HSD test). 

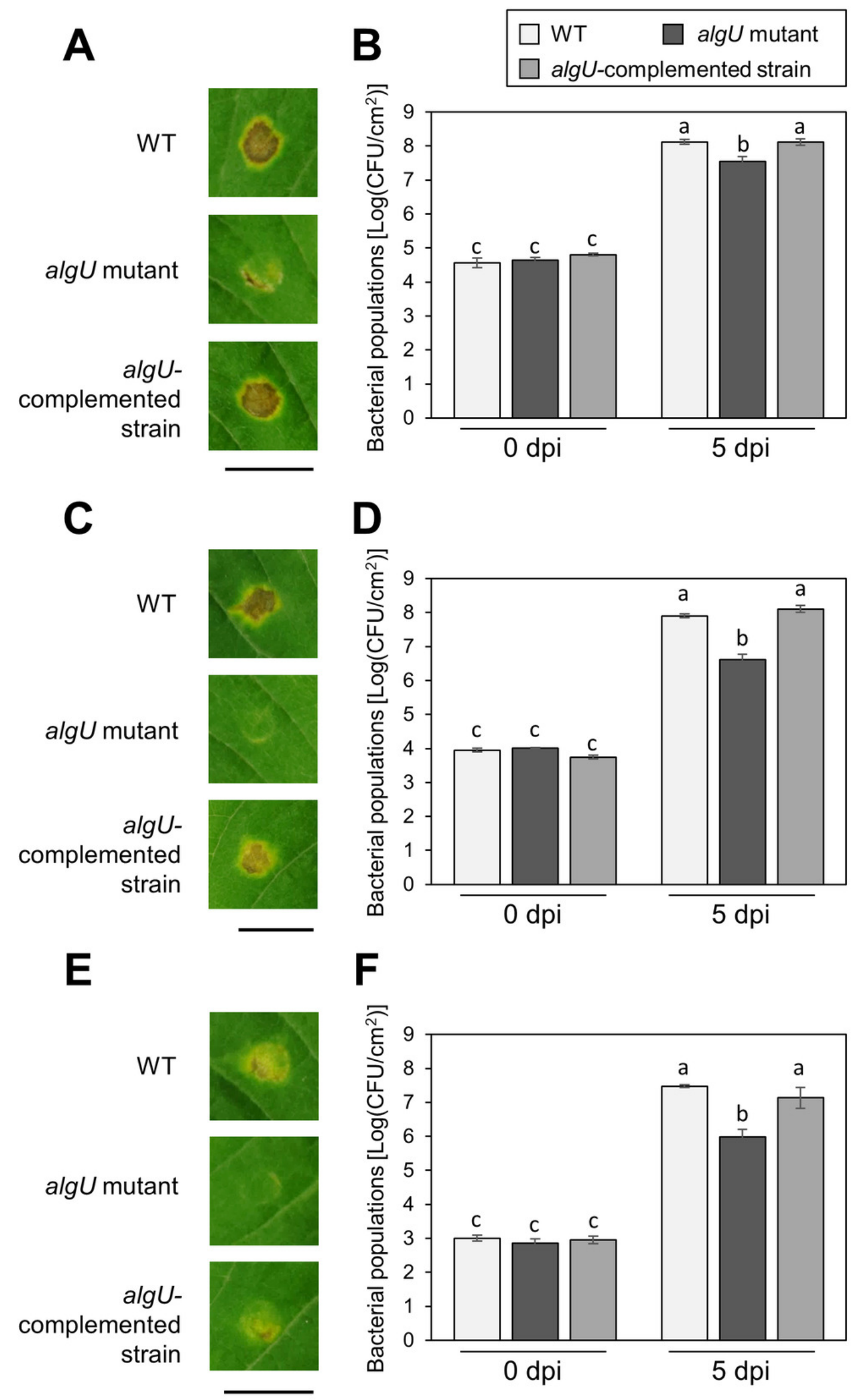
Figure 4

Gene expression profiles involved in the virulence of Pseudomonas savastanoi pv. glycinea (Psg) wild-type (WT) and algU mutant in liquid HSC broth.

Psg WT and algU mutant were grown in HSC broth for 3 and $48 \mathrm{~h}$, adjusted to an $\mathrm{OD}_{600}$ of 0.1 , and grown again in fresh HSC broth for $3 \mathrm{~h}$. Gene expression was normalized using the housekeeping gene Psg outer membrane lipoprotein I (oprl) by real-time quantitative reverse transcription-polymerase chain reaction (RT-qPCR) with gene-specific primer sets

(Supplementary Table S1). (A) cmaA, (B) cfl, (C) corR, (D) hrpL, (E) flic, and (F) algD. Vertical bars indicate the standard error for three biological replicates. The different letters (a-c) indicate a significantly statistical difference $(P<0.05$, Turkey's HSD test).
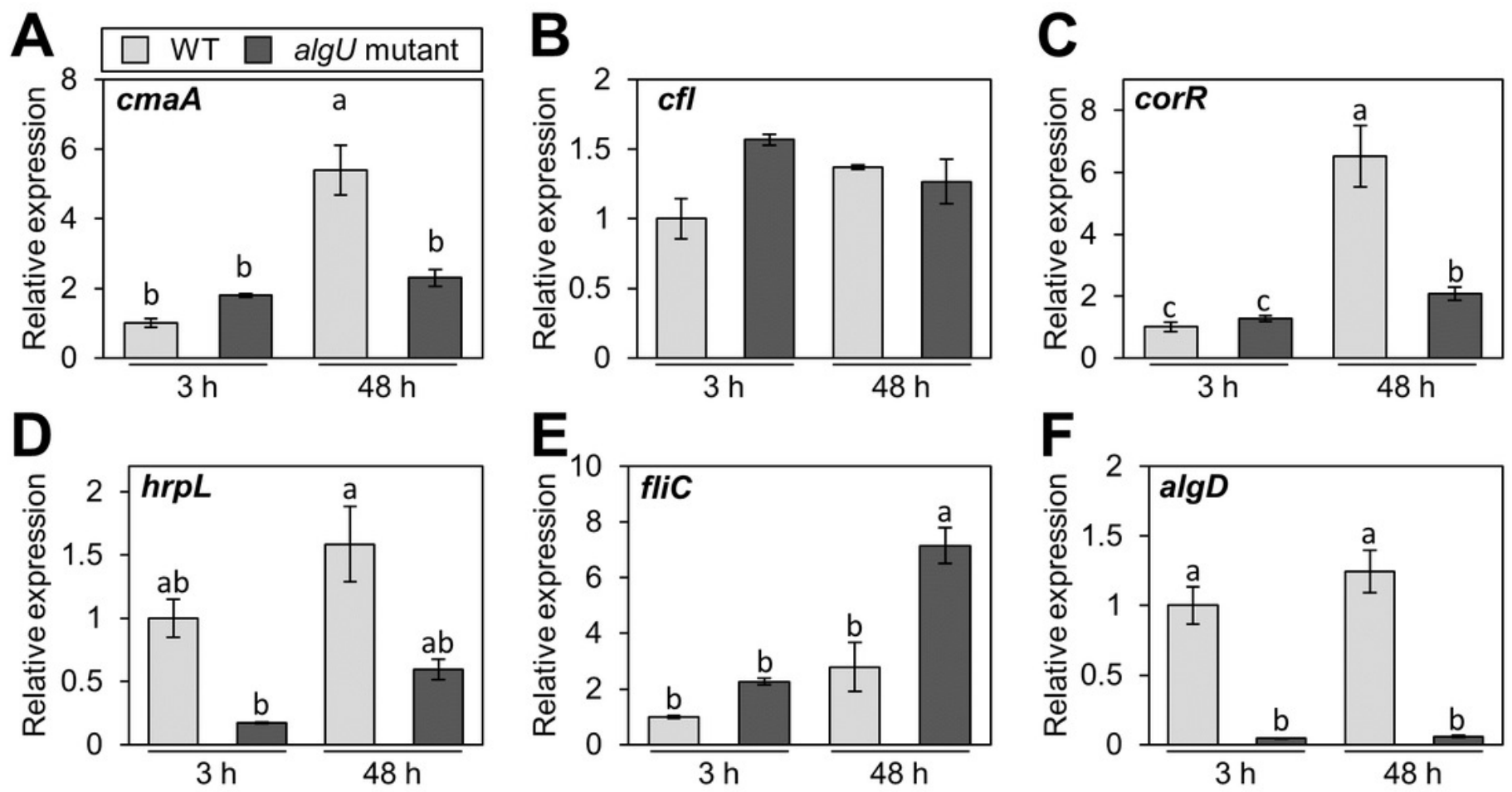


\section{Figure 5}

COR quantification of Pseudomonas savastanoi pv. glycinea (Psg) wild-type (WT), the algU mutant, and the algU-complemented strain.

(A) Observation of hypertrophy-inducting activity on potato tuber tissue inoculated with Pseudomonas savastanoi pv. glycinea (Psg) wild-type (WT), COR-defective mutants (cmaA and cfa6), the algU mutant, and the algU-complemented strain. Potato tuber discs were inoculated using toothpicks by placing the tips in the Psg WT, cmaA, cfa6, algU mutant, and the algU-complemented strain on a KB medium plate and then placing the toothpick on the potato tuber disc. Photographs were taken at $5 \mathrm{dpi}$. (B) COR quantification of Pseudomonas savastanoi pv. glycinea (Psg) wild-type (WT) and the algU mutant grown in liquid HS broth by HPLC. Psg WT, the algU mutant, and the algU-complemented strain were cultured in HSC broth for 7 days. HPLC analysis was conducted by a Shimadzu LC20A system equipped with a Symmetry C8 column. COR in the culture supernatant was identified, as compared with authentic COR as the standard. Vertical bars indicate the standard error for three biological replicates. Asterisks indicate a significant difference from WT in a $t$ test $(* * P<0.01)$. N.D. indicates not detected by HPLC. 
A

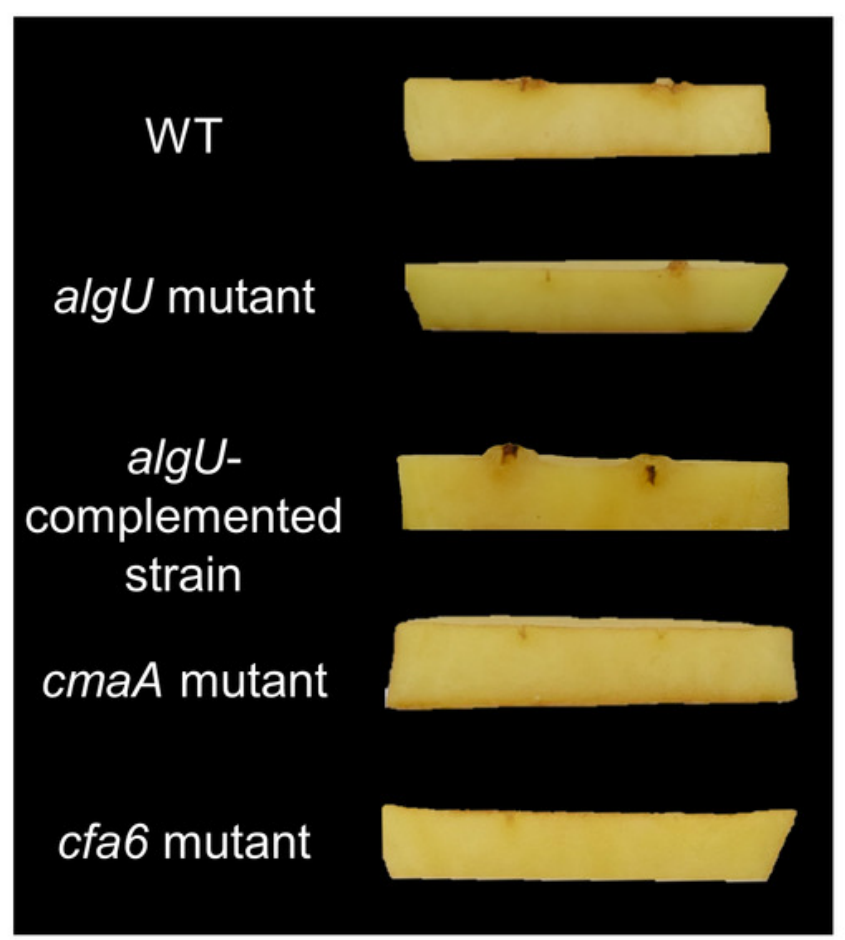

B

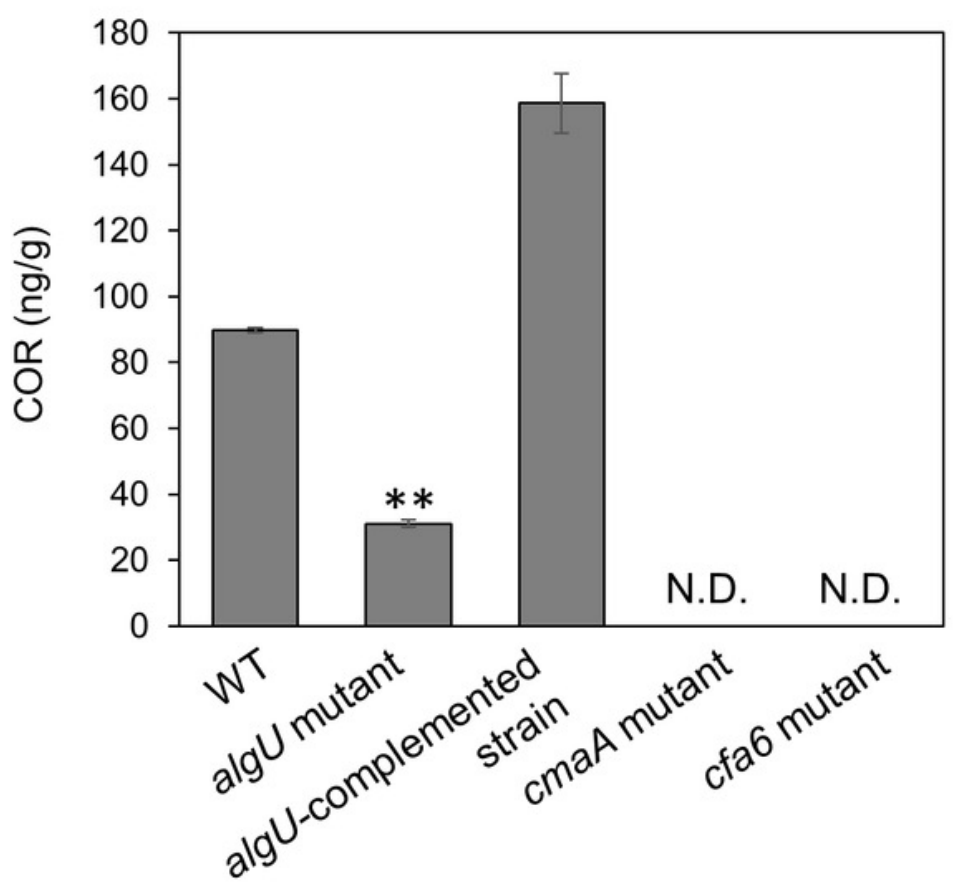




\section{Figure 6}

Biofilm biomass measurement of Pseudomonas savastanoi pv. glycinea (Psg) wild-type (WT) and the algU mutant with crystal violet (CV) grown in LB broth at $28^{\circ} \mathrm{C}$ for 24,48 , 72 , and $96 \mathrm{~h}$.

The biofilm eluted sample's absorbance was measured at $\mathrm{OD}_{595}$. Vertical bars indicate the standard error for three biological replicates. Asterisks indicate a significant difference from WT in a $t$ test $(* P<0.05, * * P<0.01)$.

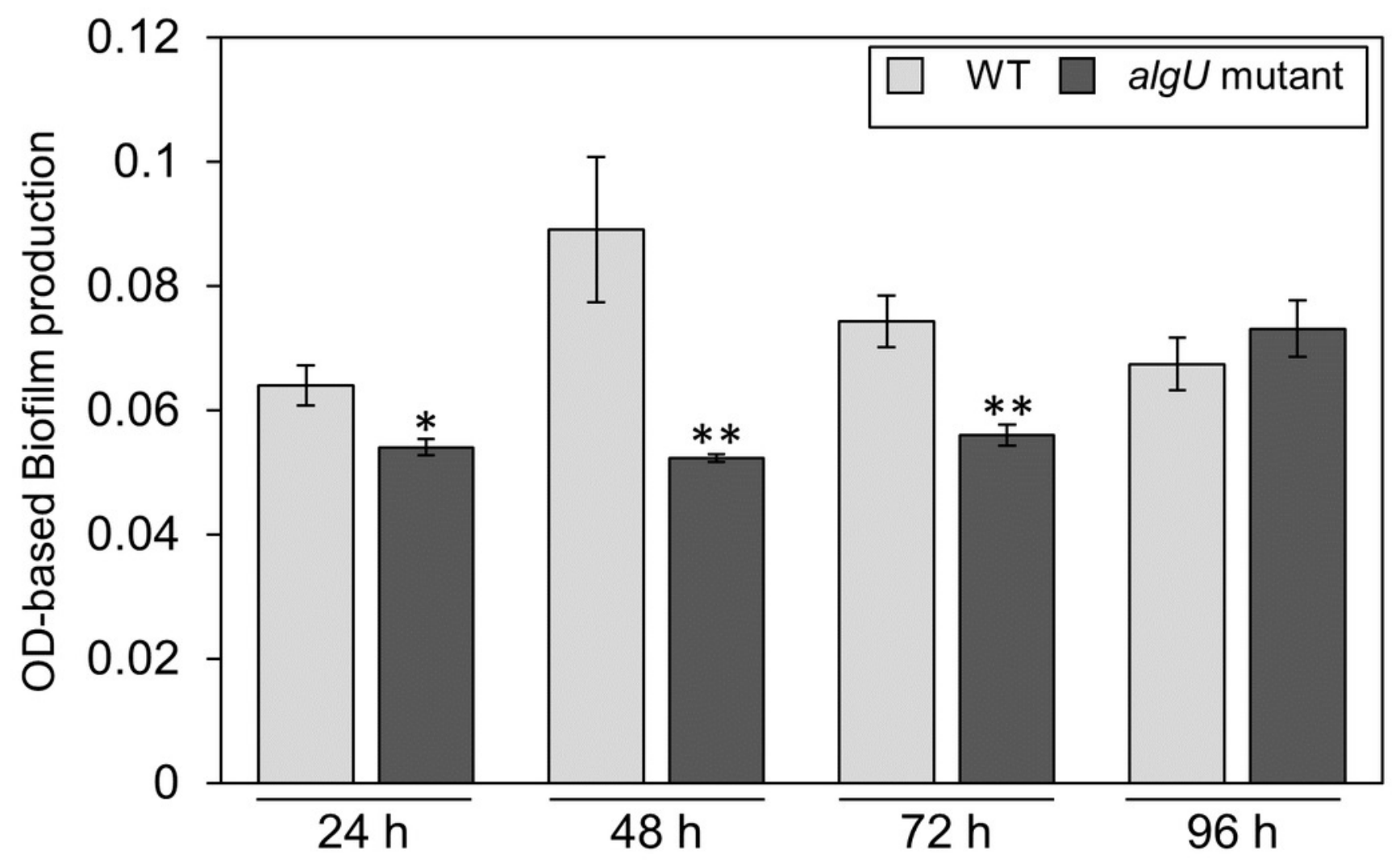

